\title{
Vascular function and arginine and dimethylarginines in gentamicin-induced renal failure: A possible effect of heme oxygenase-1 inducer hemin
}

\begin{tabular}{|r|l|}
\hline Journal: & Canadian Journal of Physiology and Pharmacology \\
\hline Manuscript ID & cjpp-2016-0578.R1 \\
\hline Manuscript Type: & Article \\
\hline Complete List of Authors: & $\begin{array}{l}\text { Aycan Ustyol, Esra; Istanbul Universitesi Istanbul Tip Fakultesi, } \\
\text { Biochemistry } \\
\text { Kabasakal, Merve; Istanbul Universitesi Eczacilik Fakultesi } \\
\text { Bekpinar, Seldag; Istanbul Faculty of Medicine, Biochemistry } \\
\text { Alp Ylldırm, Ilkay ; Istanbul Universitesi Eczacilik Fakultesi, Pharmacology } \\
\text { Tepe, Ozge; Istanbul Universitesi Istanbul Tip Fakultesi, pathology } \\
\text { Giris, Murat; Istanbul Universitesi Istanbul Tip Fakultesi, Biochemistry } \\
\text { Ozluk, Yasemin; Istanbul Universitesi Istanbul Tip Fakultesi, Pathology } \\
\text { Unlucerci, Yesim; Istanbul Universitesi Istanbul Tip Fakultesi, Biochemistry } \\
\text { Uydes Dogan, B. Sonmez; Istanbul Faculty of Pharmacy, Pharmacology } \\
\text { Uysal, Mujdat; Istanbul Universitesi Istanbul Tip Fakultesi, Biochemistry }\end{array}$ \\
\hline Keyword: & $\begin{array}{l}\text { gentamicin, vascular reactivity, heme oxygenase 1, dimethylarginines, } \\
\text { oxidative stress }\end{array}$ \\
\hline \multicolumn{2}{|c}{} \\
\hline \multicolumn{2}{|c|}{} \\
\hline
\end{tabular}




\section{Vascular function and arginine and dimethylarginines in gentamicin-induced renal failure: A possible effect of heme oxygenase-1 inducer hemin}

Esra Aycan-Ustyol ${ }^{1}$, Merve Kabasakal ${ }^{3}$, Seldag Bekpinar ${ }^{1 *}{ }^{*}$, F. Ilkay Alp-Yıldırım $^{3}$, OzgeTepe ${ }^{2}$, Murat Giris $^{1}$, Yasemin Ozluk ${ }^{2}$, Yesim Unlucerci ${ }^{1}$, B. Sonmez Uydes-Dogan ${ }^{3}$, Mujdat Uysal ${ }^{1}$

${ }^{1}$ Department of Biochemistry, ${ }^{2}$ Department of Pathology, Istanbul Faculty of Medicine, Istanbul University, Capa 34093, Istanbul, Turkey, ${ }^{3}$ Department of Pharmacology, Faculty of Pharmacy, Istanbul University, Beyazit, 34116, Istanbul, Turkey.

*Corresponding author: Seldag Bekpinar, Department of Biochemistry, Istanbul Faculty of Medicine, Istanbul University, Capa 34093, Istanbul, Turkey.

E-mail: seldabekpinar@hotmail.com (bekpinar@istanbul.edu.tr) 


\begin{abstract}
Increased oxidative stress and disturbance in nitric oxide bioavailability lead to endothelial dysfunction and cardiovascular complication in renal disease. Gentamicin (GM), a commonly used antibiotic exhibits a toxic effect on renal proximal tubules. Prevention of its nephrotoxicity is important. Therefore, we investigated whether heme oxygenase (HO)-1 induction influenced kidney and vascular function in GM-administered rats. GM $(100 \mathrm{mg} / \mathrm{kg} / \mathrm{day} ; \mathrm{ip})$ was given to rats alone or together with hemin $(20 \mathrm{mg} / \mathrm{kg} /$ alternate days; ip.) for 14 days. Plasma and kidney L-arginine, asymmetric dimethylarginine (ADMA) and symmetric dimethylarginine (SDMA) as well as kidney 4hydroxynonenal (HNE) levels and myeloperoxidase (MPO) activity were measured. Histopathologic examinations of kidney and relaxation and contraction responses of aorta were also examined. GM increased serum SDMA, urea nitrogen (BUN), and creatinine levels and caused histopathologic alterations in kidney. GM elevated HO-1 protein and mRNA expressions, 4-HNE level, MPO activity and decreased antioxidant enzyme activities and L-arginine levels in kidney. Decreased relaxation and contraction were detected in the aorta. Hemin restored renal oxidative stress and inflammatory changes together with vascular dysfunction, but did not affect SDMA, BUN, and creatinine levels. It is concluded that HO-1 induction may be effective in improving renal oxidative stress, inflammation and vascular dysfunction mediated by GM.
\end{abstract}

Keywords: gentamicin; vascular reactivity; heme oxygenase 1; dimethylarginines; oxidative stress 


\section{Introduction}

Gentamicin (GM) is an aminoglycoside antibiotic utilized to treat Gram-negative bacterial infections. Its major adverse effect, which limits its clinical use, is the toxic effect on the kidneys (Quiros et al. 2001). The preferential accumulation of gentamicin in the renal proximal tubules accounts for nephrotoxicity (Lopez-Novoa et al. 2011). Although the exact mechanism of GM-induced nephrotoxicity is unknown, studies have implicated increased oxidative stress in the resultant renal damage (Morales et al. 2010; Quiros et al. 2001). Prevention of nephrotoxic effect of GM is extremely important because of its widespread clinical use. Various antioxidant compounds have been shown to mitigate GM-induced tubular damage [Kadkhodaee et al. 2005; Pedraza-Chaverri et al. 2003).

Heme oxygenase $(\mathrm{HO})$ is the rate-limiting enzyme in the breakdown of heme into carbon monoxide, iron and biliverdin. It can be induced by various stimuli including hypoxia, radiation, hydrogen peroxide, endotoxin and some metals, and is believed to be an important defense mechanism against such injuries (Agarwal et al. 2013; Correa-Costa et al. 2012). The antioxidant and antiinflammatory effects of HO-1 have been reported to be due to the elimination of pro-oxidant heme and the biologic activities of bilirubin and carbon monoxide. HO-1 induction has also been suggested to play a healing role in acute and chronic renal failure (Correa-Costa et al. 2012; Desbuards et al. 2009; Nath 2014). The effect of HO-1 induction on GM- dependent nephrotoxicity was also examined (Duarte et al. 2016; Sue et al. 2009; Taye and Ibrahim 2013).

Vascular endothelium is an active organ that produces vasodilator and vasoconstrictor molecules such as nitric oxide (NO), prostacyclin, and endothelin, which balance each other under normal conditions. A shift in the relative contributions of the endothelium-derived vasoactive molecules may be associated with arterial disease. Impaired NO bioavailability, the increases in oxidative stress and cytokine production have been well known to lead to endothelial dysfunction, which is an early feature of vascular complications in several diseases such as diabetes and coronary heart disease (Celermajer et al. 1992; Endemann and Schiffrin 2004; Liu et al. 2012). There is growing evidence that renal failure is associated with impaired endothelial function ( Köhler et al. 2005; Mori-Kawabe et al. 2015; Nguy et al. 2012). Although it is not clear how impaired renal function affects vascular endothelium, the balance between the substrate and inhibitors for NO synthesis such as L-arginine, asymmetric dimethylarginine (ADMA) and symmetric dimethylarginine (SDMA) may be altered in this pathologic condition.

The aim of this study was to investigate whether induction of HO-1 through hemin treatment could protect against GM-induced renal toxicity in rats. For this purpose, HO-1 expression, oxidant/antioxidant status, and histologic appearance were examined in renal tissue of rats. For 
assessing the effects of GM and/or hemin treatments on vascular system, the vascular reactivity and plasma and renal tissue levels of L- arginine, ADMA and SDMA were also measured.

\section{Materials and methods}

\section{Animals and treatments}

Male Wistar rats weighing 250-300 g were used in this study. All rats were housed in a room maintained at a constant temperature $\left(20 \pm 2^{\circ} \mathrm{C}\right)$ with free access to food and water, and subjected to a $12 \mathrm{~h}$ light/dark cycle. All the protocols performed in the present study were carried out under the supervision of Animal Care and Use Committee of Istanbul University. All authors in this study gave assurance that the animals were cared for in accordance with the guidelines of the Canadian Council on Animal Care (Guide to the Care and Use of Experimental Animals, Vol. 1 (2nd ed., 1993). Twenty-eight rats were randomly divided into four groups of 6 or 8 animals each: (1) Control group: an equal volume of vehicle was injected to rats, (2) Hemin group: hemin was dissolved in $1 \mathrm{ml}$ of 0.2 $\mathrm{M} \mathrm{NaOH}$, adjusted the $\mathrm{pH}$ to 7.4 with $1 \mathrm{M} \mathrm{HCl}$, and diluted with $0.9 \% \mathrm{NaCl}$. Hemin $(20 \mathrm{mg} / \mathrm{kg}$ body weight; i.p.) was injected alternate days to rats for two weeks, (3) GM group: rats were daily given gentamicin (100 mg/kg body weight, diluted in saline; i.p.) for two weeks. (4) GM + Hemin group: first hemin dose was injected $24 \mathrm{~h}$ before GM treatment and then was continued to be injected alternate days together with daily GM for two weeks. GM and hemin doses were applied at a maximum volume of $1 \mathrm{ml}$ by taking into account body weight of rats. The animals were anesthetized with sodium pentobarbital $(50 \mathrm{mg} / \mathrm{kg}$, i.p.) and blood was taken by cardiac puncture following an overnight fasting period. Serum and plasma were obtained by centrifugation at 1500xg for 10 min. Kidney tissues were rapidly removed, washed in ice-cold saline and snap-frozen in liquid nitrogen and all samples then stored at $-80^{\circ} \mathrm{C}$ until used for biochemical assays and expression analysis. The thoracic aorta from each rat was isolated for evaluating vascular functions.

Serum urea nitrogen (BUN) and creatinine levels, ALT and AST activities

Serum BUN and creatinine levels and alanine aminotransferase (ALT) and aspartate aminotransferase (AST) activities were determined using a Roche autoanalyzer.

\section{Serum HO-1 assay}

The concentrations of HO-1 were determined using an enzyme-linked immunosorbent assay (ELISA) (Bioassay Technology Laboratory, Shanghai, China). 


\section{Plasma and kidney ADMA, SDMA and L-arginine assays}

The concentrations of ADMA, SDMA and L-arginine in plasma samples with EDTA were determined with high-performance liquid chromatography (HPLC). Samples were treated with o-phtaldialdehyde to convert methylarginines to a fluorescent compound (Teerlink 2005). For the determination of the methyl arginines in kidney, tissue was homogenized in 4 volume sodium phosphate buffer (100 mM, $\mathrm{pH}$ : 6.5). Two hundred fifty microliters of tissue homogenate were mixed with equal volume of perchloric acid (1.2 M). After centrifugation, L- arginine, ADMA and SDMA in supernatant were determined with HPLC, as with the plasma.

\section{Kidney 4-HNE assay}

The tissue homogenates $(10 \mathrm{mg} / \mathrm{mL})$ in phosphate-buffered saline (PBS) were used to determine 4HNE levels using an ELISA kit (Bioassay Technology Laboratory, Shanghai, China) and results were given as nanogram / mg of protein.

\section{Kidney glutathione assay}

Glutathione (GSH) levels were measured with 5, 5-dithiobis-(2-nitrobenzoate) at $412 \mathrm{~nm}$ in kidney homogenates $(10 \%$, in $0.15 \mathrm{M} \mathrm{KCl})$ (Beutler et al. 1963). The results were given as $\mu \mathrm{mol} / \mathrm{g}$ tissue weight.

\section{Kidney SOD and GSH-Px activities}

Superoxide dismutase (SOD) and glutathione peroxidase (GSH-Px) activities were determined in postmitochondrial fraction, which was prepared by centrifuging tissue homogenate (10\% in $0.15 \mathrm{M} \mathrm{KCl})$ in 10000 g, 15 minutes. SOD activity was assayed by its ability to increase the effect of riboflavinsensitized photo-oxidation of o-dianisidine (Mylroie et al. 1986). GSH-Px activity was measured using cumene hydroperoxide as substrate (Lawrence and Burk 1976). Protein levels were determined by bicinchoninic acid (Smith et al. 1985).

\section{Kidney myeloperoxidase (MPO) activity}

Two hundred mg of kidney tissue was homogenized in $0.5 \%$ hexadecyltrimethylammonium bromide in $50 \mathrm{mM}$ phosphate buffer, $\mathrm{pH}: 6$. After freeze-thawing three times and centrifuging at $40000 \mathrm{xg}$, the supernatant was used to determine MPO activity (Rachmilewitz et al. 1993). One hundred $\mu$ l of the supernatant was mixed with $2.9 \mathrm{ml}$ of $50 \mathrm{mM}$ phosphate buffer containing $0.53 \mathrm{mM}$ 0-dianisidine 
and $0.15 \mathrm{mM} \mathrm{H}_{2} \mathrm{O}_{2}$. The change in absorbance at $460 \mathrm{~nm}$ was measured every minute for 3 minutes in $37^{\circ} \mathrm{C}$. The results were expressed as $\mu \mathrm{mol}$ peroxide/min.

Kidney dimethylarginine dimethylaminohydrolase (DDAH) activity

DDAH activity was measured using a colorimetric assay to measure the rate of citrulline production (Tain and Baylis 2007). One hundred $\mu \mathrm{L}$ ( $2 \mathrm{mg}$ total protein) of homogenate was incubated with 1 $\mathrm{mM}$ ADMA for $45 \mathrm{~min}$ at $37^{\circ} \mathrm{C}$. After deproteinization, the supernatant was incubated with equal volume of color reagent at $60^{\circ} \mathrm{C}$ for $110 \mathrm{~min}$. Color reagent consists of a mixture of 1 part of the oxime $\left(0.8 \%\right.$ diacetyl monoxime in $5 \%$ acetic acid) and 2 parts antipyrine $/ \mathrm{H}_{2} \mathrm{SO}_{4}(0.5 \%$ antipyrine in $50 \% \mathrm{H}_{2} \mathrm{SO}_{4}$ ) reagent. The absorbance was measured at $466 \mathrm{~nm}$. DDAH activity is expressed as nanomoles of citrulline/gram of protein/ minute.

\section{Protein expression of $\mathrm{HO}-1$ in kidney tissue}

To detect HO-1, kidney tissues were lysed in modified RIPA buffer (50 mM TrisHCl, pH 7.4, 0.25\% Nadeoxycholate, 10 \% SDS, 150 mM NaCl, 1 mM EDTA, 1 mM PMSF, 1\% Triton X-100, 1\% glycerol, 1 $\mu \mathrm{g} / \mathrm{mL}$ of aprotinin, $1 \mu \mathrm{g} / \mathrm{mL}$ leupeptin, $1 \mu \mathrm{g} / \mathrm{mL}$ pepstatin $\mathrm{A}, 1 \mu \mathrm{g} / \mathrm{mL}$ soybean trypsin inhibitor, $0.5 \mathrm{mM}$ dithiothreitol, and $1 \mathrm{mM} \mathrm{NaF}$ ). Sodium dodecyl sulfate (SDS)-polyacrylamide gel electrophoresis (PAGE) was performed using the BioRad Mini Protean III gel system. Equal amounts of protein from each sample $(50 \mathrm{mg} /$ well) were loaded onto a $10 \%$ SDS-PAGE, and proteins were then transferred to polyvinylidene difluoride (PVDF) membranes. Following incubation, membranes were washed with PBS containing 0.01\% Tween 20 (PBS-T) and then exposed to secondary antibodies. After washing, blots were visualized using the enhanced chemiluminescence (ECL) kit (Amersham Pharmacia, Piscataway, NJ) according to the manufacturer's protocol. The relative densities of the bands were quantified using the VilberLourmat-Bio-Profil imaging system (VilberLourmat Biotechnology, Marne-la-Vallée, France). The following primary antibodies were used: rabbit polyclonal anti-HO-1 (SC-10789, Santa Cruz Biotechnology), mouse monoclonal anti- $\alpha$ actin (SC-32251; Santa Cruz Biotechnology). Secondary antibodies included goat anti-rabbit IgG-HRP (SC-2030; Santa Cruz, Biotechnology) and goat anti-mouse IgG-HRP (SC-2005, Santa Cruz Biotechnology).

MRNA expression of HO-1 in kidney tissue

The kidney tissue was homogenized using a MagnaLyser instrument (Roche Applied Science Diagnostics). Total RNA was isolated using Ambion Pure Link RNA Mini kit (Life Technologies, Carlsbad, Calif.) and the quality and quantity of RNA were checked by NanoDrop 2000 UV-Vis spectrophotometer (Thermo Scientific, Wilmington, Denver, USA). cDNA was synthesized with RT2 
HT First Strand cDNA kit (QIAGEN, Venlo, Netherlands). The primers for HO-1 (Forward: TTCTCCGATGGGTCCTTACA and Reverse: TTGAGACAGCTGCCACATTAG), and the housekeeping gene, $\beta$ - actin (Forward: CCGCGAGTACAACCTTCTTG and Reverse: CAGTTGGTGACAATGCCGTG), were purchased from QIAGEN. The qPCR was performed using qPCR Green Master with UNG/low ROX kit (Jena Bioscience, GmbH, Jena, Germany) in a real-time polymerase chain reaction (PCR) system (Stratagene Mx3005P qPCR System; Agilent Technologies, Santa Clara, California). The expression levels of mRNAs were quantified using the standard curve method. Analytical data were adjusted, with the expression levels of mRNA of beta-actin used as an internal control.

\section{Vascular functions in isolated thoracic aorta}

The thoracic aorta from each rat was isolated and immediately placed into cold Krebs solution of the following composition (in $\mathrm{mM}$ ): $\mathrm{NaCl}, 118 ; \mathrm{KCl}, 4.7 ; \mathrm{KH}_{2} \mathrm{PO}_{4}, 1.2 ; \mathrm{MgSO}_{4} \cdot 7 \mathrm{H}_{2} \mathrm{O}, 1.1 ; \mathrm{CaCl}_{2}, 2.5$; $\mathrm{NaHCO}_{3}, 25$; glucose, 10; and disodium EDTA, 0.026. The aortic rings of 2-3 mm in length were mounted in an organ bath containing Krebs solution at $37^{\circ} \mathrm{C}$ and aerated with $95 \% \mathrm{O}_{2}$ and $5 \% \mathrm{CO}_{2}$. Two rings were prepared from each aorta and studied in parallel. The preparations were allowed to equilibrate for approximately $1.5 \mathrm{~h}$, with renewal of the bathing solution every 15 min under passive stretch of $1 \mathrm{~g}$. To prove the standardization of the aortic rings, 2 reproducible contractions were obtained with $\mathrm{KCl}(40 \mathrm{mM})$, and the rings that produced a tension of less than $1 \mathrm{~g}$ were not included in the experiments. Functional integrity of the endothelium was tested by adding acetylcholine (ACh; $10^{-6} \mathrm{M}$ ) to phenylephrine (Phe; $10^{-6} \mathrm{M}$ )- precontracted aortic rings (Akar et al. 2012; Sönmez UydeşDoğan et al. 2005). The cumulative concentration-response curve of Phe $\left(10^{-9}\right.$ to $\left.10^{-4} \mathrm{M}\right)$ was constructed in aortic rings. The relaxant effects of $\mathrm{ACh}\left(10^{-9}\right.$ to $\left.10^{-4} \mathrm{M}\right)$ and sodium nitroprusside (SNP; $10^{-9}$ to $10^{-4} \mathrm{M}$ ) were studied in rings constricted submaximally with Phe $\left(10^{-6} \mathrm{M}\right)$.

\section{Histologic analysis}

Kidney tissue was removed immediately and fixed in $10 \%$ neutral formalin solution, then embedded in paraffin wax and sectioned ( $4 \mu \mathrm{m}$ thickness) for histopathologic evaluation. Kidney sections were stained with hematoxylin-eosin (H\&E) and PAS (periodic acid-Schiff) using a standard protocol, and then analyzed under light microscopy. In addition, kidney sections of each rat were scored between 0 and 3 for severity of tubular inflammation, necrosis and degeneration and were evaluated statistically.

\section{Statistical analysis}

The values are the mean $\pm \mathrm{SE}$, and $n$ indicates the number of rats used in the experiments. Mean values were compared between groups by using Student's paired $t$-test and one-way analysis of variance (ANOVA) followed by a Tukey-Kramer multiple comparisons test for normally-distributed 
variables, where appropriate. If the data were not normally distributed, a Kruskal-Wallis test followed by the Mann-Whitney $U$ was used. A value for $p<0.05$ was considered statistically significant.

The contractile response to Phe was calculated as the increase in tension (g). The relaxation responses to ACh and SNP were expressed as percent relaxations of the precontraction induced by Phe. $E_{\max }$ is the maximum responses (relaxation or contraction) achieved by the vasoactive agents used in the experimentations. Sensitivities of the aortic rings to relaxant and contractile agents were calculated as the effective concentration that elicited $50 \%$ of the maximal response $\left(\mathrm{EC}_{50}\right.$ value) from the individual concentration-effect curves, and expressed as the negative $\log \mathrm{EC}_{50}$ values.

Results

Kidney $\mathrm{HO}-1$ expression and its serum levels

GM treatment by itself caused significant increases in protein and mRNA expressions of HO-1 in the kidney (Figure $1 \mathrm{~A}$ and $\mathrm{B}$ ). When treated in combination with $\mathrm{GM}$, hemin did not cause a further increase in HO-1 expression. Hemin treatment alone also elevated its protein expression. Increased HO-1 levels were detected in serum of hemin treated groups with or without GM (Figure 2).

\section{Kidney function characteristics}

GM treatment increased kidney weight and kidney index. This treatment also raised BUN and serum creatinine levels, whereas it did not affect the circulating activities of ALT and AST. Hemin administration did not alter the increases in circulating levels of BUN and creatinine, but brought kidney weight to normal values in GM-injected rats (Table 1).

\section{Renal oxidant and inflammatory stress}

GM treatment alone increased 4-HNE levels, a sensitive marker of lipid peroxidation, and MPO activity in renal tissue of rats. Although GSH levels remained unchanged, renal SOD and GSH-Px enzymes were decreased following GM treatment. Hemin administration remarkably restored the GM-induced increments in 4-HNE levels and MPO activity. It elevated renal GSH levels over the control values but did not influence GM-induced changes in antioxidant enzyme activities (Table 2). 
L-arginine, ADMA, and SDMA levels in plasma and renal tissue

GM treatment did not alter plasma L-arginine and ADMA levels and L-arginine/ADMA ratio as compared with the control (Table 3). However, this treatment increased SDMA levels and thus decreased L-arginine/SDMA ratio in plasma. On the other hand, plasma SDMA value was found significantly correlated with both BUN $(r=0.518, p=0.007)$ and creatinine $(r=0.530, p=0.005)$. When measured these parameters in kidney tissue, renal L-arginine and SDMA contents were detected to be decreased with GM treatment. GM also markedly diminished the DDAH enzyme activity in kidney.

Hemin treatment did not improve the increase in plasma SDMA, rather it led to a moderate healing in L-arginine /SDMA ratio in GM group. However, this treatment did not affect GM-mediated changes in L-arginine and SDMA contents in renal tissue.

\section{ACh-induced relaxations and Phe-induced contractions in aortic rings}

Our findings related to the vascular function are shown in Figure 3 and Tables 4 and 5. ACh-induced relaxations, specifically at the low concentrations $\left(10^{-9}-10^{-7} \mathrm{M}\right)$, were significantly decreased in the aortic rings from GM-treated rats, as compared with the control values whereas, the maximum relaxations were unchanged (Figure 3). Hemin co-treatment significantly increased the endothelial relaxation to $\mathrm{ACh}$, both in terms of potency $\left(\mathrm{EC}_{50}\right)$ and maximal response $\left(E_{\max }\right)$ (Table 4 and Figure3). The values for endothelium-independent relaxation to SNP were similar for all groups (Table 4). Pheinduced maximal contractions, both in terms of potency $\left(E_{50}\right)$ and maximal response $\left(E_{\max }\right)$ were decreased in aortic rings from GM-treated rats (Table 5 and Figure 3). There was also a significant decrement in contractile responses to $\mathrm{KCl}$ in terms of $E_{\max }$ values in $\mathrm{GM}$ treated group (Table 5). Hemin co-treatment restored the maximal contraction to both Phe and $\mathrm{KCl}$ in terms of maximal response $\left(E_{\max }\right)$ when compared with the GM-treated rats.

\section{Histopathologic evidence of kidney}

Histologic examination of the kidney tissues showed that GM treatment resulted in tubular inflammation, degeneration, and minimal necrosis (Figure 4). A semiquantitative analysis of the histopathologic changes of kidney tissues was also scored as shown in Table 6. According to this, hemin therapy remarkably reduced GM-mediated inflammation. Tubular degeneration and necrosis also tended healing following hemin co-treatment but this tendency was not statistically significant.

\section{Discussion}

In our study, daily GM (100 mg/kg/day, i.p) application to rats for 2 weeks caused increments in circulating levels of BUN, creatinine, and SDMA. Histopathologic examination indicated a common 
leukocyte infiltration in the tubulointerstitial field and degeneration and necrosis in tubule epithelial cells. Increased renal MPO activity, an enzyme mainly released by activated neutrophils also supported renal inflammation. Alterations in the renal prooxidant-antioxidant balance were also estimated as a response to GM. For this purpose, 4-HNE, a product of lipid peroxidation, and GSH levels as well as SOD and GSH-Px activities were measured in renal tissue. Accordingly, increased 4HNE contents and diminished antioxidant enzyme activities were detected after GM exposure, which suggesting that oxidative stress may be one of the causes of renal injury induced by GM. Our results are in accordance with previous studies (Kadkhodaee et al. 2005; Karahan et al. 2005; PedrazaChaverri et al. 2003; Suresha and Srinivasan 2014).

In the present study, we also evaluated the effect of GM-induced kidney damage on vascular reactivity and some parameters that are thought to be effective in NO production. Vascular reactivity was evaluated in experimental conditions by measuring relaxation and contractile responses in isolated rat aortic rings. As far as we know, no studies have investigated vascular reactivity in GMtreated animals, but adenine, which causes tubular necrosis like gentamicin, has been found to adversely affect vascular reactivity (Mori-Kawabe et al. 2015; Nguy et al. 2012). In addition, impaired endothelial relaxation response and hypertension was observed in a chronic renal failure model induced by $5 / 6$ nephrectomy (Hasdan et al. 2002; Köhler et al. 2005) and by ischemia-reperfusion (Kingma et al. 2006). These results indicated that the renal failure may affect vascular function. In the present study, GM administration to rats significantly reduced the relaxations to low concentrations of $\mathrm{ACh}$, which is an endothelium-dependent vasodilator, in aortic rings without affecting maximal relaxant responsiveness. This significant reduction, indeed, refers to an impairment in endotheliumdependent relaxing mechanisms possibly due to a decrease in the bioavailability of NO, induced by the oxidant properties of GM. It is well documented previously that excessive formation of free radicals reduces the relaxant influence of NO on vascular smooth muscle via decreasing its biovailaibility and lead to endothelial dysfunction (Endemann and Schiffrin 2004). On the other hand, the responses to SNP, which is an endothelium independent vasodilator and generates relaxation by a direct effect on smooth muscle cell (SMC), were unchanged. Concerning the contractile responses, both receptor-and non-receptor-mediated contractions induced by Phe and $\mathrm{KCl}$, respectively, were also decreased in the aortic rings of GM group, which indicates that there were general abnormalities in the contractile apparatus of SMC or in its regulation in GM- treated rats. These disturbances indicate a direct adverse effect of GM on the vascular system as well as on the kidney.

Kidney plays an important role in NO homeostasis. Circulating levels of L-arginine, the only limiting substrate for nitric oxide synthase (NOS), is mainly synthesized in the kidney. Proximal tubules of kidney are a predominant site of its synthesis (Dhanakoti et al. 1990; Wu and Morris 1998). In 
addition, L- arginine is almost completely absorbed from urine by the epithelium of proximal tubules and then returns to the circulation. ADMA, a competitive endogenous nitric oxide synthase (NOS) inhibitor is mainly metabolized in kidney and liver. The kidney contains large quantities of DDAH, the only known enzyme degrading ADMA (Palm et al. 2007). SDMA, other methyl arginine derivative may adversely affect the formation of NO by interfering with the transport of L-arginine into cells such as the endothelium (Closs et al. 1997). Moreover, because SDMA is removed from the body via the kidneys without undergoing changes, its accumulation in blood is considered a sensitive indication of renal failure (Busch et al. 2006; Kielstein et al. 2006). In light of these data, it was reasonable to assume that GM-induced renal injury may affect L-arginine and dimethylarginine levels. For this reason, we evaluated the plasma and renal levels of these substances. According to our results, GMinduced renal failure did not alter arginine levels in plasma but led to a significant reduction in its kidney values. In different acute renal injury model, low arginine content in renal tissue has also been detected (Betz et al. 2013; Sukhovershin and Gilinsky 2013). GM-induced change in tissue arginine levels might be due to its defective renal synthesis and/or tubular absorption. The lack of the linear relationship between plasma and tissue levels of arginine suggests the existence of other factors that affect its circulating levels. Indeed, experiments with dogs have shown that about $40 \%$ of circulating arginine is produced outside the kidney (Yu et al. 1996). On the other hand, we detected that plasma and renal tissue ADMA levels remained unchanged but renal DDAH enzyme was markedly inhibited in GM- treated rats. DDAH has been shown to express widely in the kidney and very sensitive to oxidative stress. For this reason, GM-induced oxidative stress and inflammation may have led to the enzyme inhibition. However, in our study, reduced renal DDAH activity in GM-treated rats was not associated with significant accumulation of ADMA in either plasma or renal tissue. We suggest that defective tubular absorption due to GM-induced renal damage may prevent the accumulation of ADMA. We also speculate that hepatic DDAH enzyme, but not renal DDAH could play more important role in regulation of plasma ADMA.

In contrast to ADMA, plasma SDMA concentration was increased in parallel with GM-induced toxicity, and was also found to be correlated with BUN and creatinine values. This was an expected result because SDMA levels are known to be elevated in patients with chronic kidney disease and in animal models (Busch et al. 2006; Kielstein et al. 2006). A marked decrease in plasma L-arginine / SDMA ratio was also found in our study. As SDMA competes with L-arginine for cellular transport, plasma L-arginine/SDMA ratio may be a more relevant indicator for evaluation of arginine supply into tissue cell for NO synthesis. Thus, correction of the L-arginine/SDMA ratio could be a promising new target to improve outcomes of acute kidney injury. 
HO-1 is a cytoprotective enzyme against oxidative stress-induced conditions. It has been shown that HO-1 induction ameliorates acute and chronic kidney injury such as ischemia-reperfusion (Chen et al. 2015), cisplatin (Al-Kahtani et al. 2014), and 5/6 nephrectomy (Desbuards et al. 2009). On the other hand, the inhibition of this enzyme was found to aggravate renal damage (Ishikawa et al. 2001; Takizawa et al. 1998).

In the present study, we aimed to determine whether HO-1 inducer hemin would limit the GMinduced renal toxicity. GM treatment by itself was capable of inducing significantly in HO-1 expression. The inflammatory milieu and cell stress generated by GM treatment might be responsible for the induction of HO-1, previously described (Duarte et al. 2016). However, when coadministered with $\mathrm{GM}$, hemin did not cause a further significant increase in HO-1 expression in renal tissue. Although hemin co-treatment did not alter renal injury test in serum such as SDMA, BUN, and creatinine, this treatment caused a significant reduction in kidney weight, MPO activity and 4-HNE levels as well as increase GSH levels in the kidneys. In addition, reduced DDAH activity returned to normal levels with hemin co-treatment. These findings show that hemin administration exhibits antioxidant and anti-inflammatory effects that lead to an improvement, at least in part, in renal histopathology in GM-treated rats. It is possible thought that hemin improves kidney failure if given for longer to the animals. Concerning the influence on vascular reactivity, hemin co-treatment restored the endothelium-dependent relaxations and receptor-and non-receptor-mediated contractions in isolated aorta. In relation, we suggest that hemin co-treatment possibly enhanced the bioavailability of NO via antioxidant mechanisms and thus, increased the sensitivity to ACh and recovered the impairment in endothelial reactivity. Regarding the recovery observed in the maximal contractions of $\alpha$-receptor agonist, Phe and voltage-gated $\mathrm{Ca}^{2+}$ channel agonist, $\mathrm{KCl}$, we propose that hemin co-treatment effectively reversed the impaired contractile machinery induced by GM. Taking account the findings that hemin co-treatment ameliorated the endothelial function and contractile reactivity in rat aorta, we reasonably suggest that hemin could improve vascular dysfunction mediated by GM. Thus, without a significant improvement in renal function, the restoration of vascular reactivity with hemin suggests its direct influence on vascular system. It is reliable to consider that induction of HO-1 in non-renal organs such as vascular, liver and spleen with hemin treatment would exhibit these accumulated favourable effects on renal and vascular tissues. In our study, the increments determined in serum HO-1 levels in both hemin-treated groups may support this assumption.

In conclusion, our findings suggest that HO-1 induction may be effective in improving renal oxidative stress, inflammation and vascular dysfunction mediated by GM. Thus, a concomitant therapeutic approach elevating HO-1 levels may allow more reliable use of this antibiotic in clinical setting. 


\section{Acknowledgments}

This work was supported by The Research Fund of Istanbul University, projects no: 52602 and 52221.

\section{References}

Agarwal, A., and Bolisetty, S. 2013. Adaptive responses to tissue injury: role of heme oxygenase-1. Trans. Am. Clin. Climatol. Assoc. 124: 111-22.

Akar, F., Uludağ, O., Aydın, A., Aytekin, Y.A., Elbeg, S., Tuzcu, M., et al. 2012. High-fructose corn syrup causes vascular dysfunction associated with metabolic disturbance in rats: protective effect of resveratrol. Food Chem. Toxicol. 50: 2135-41.

Al-Kahtani, M.A., Abdel-Moneim, A.M., Elmenshawy, O.M. and El-Kersh, M.A. 2014. Hemin attenuates cisplatin-induced acute renal injury in male rats. Oxid. Med. Cell Longev. 2014: 476430.

Betz, B., Möller-Ehrlich, K., Kress, T., Kniepert, J., Schwedhelm, E., Böger, R.H,, et al. 2013. .Increased symmetrical dimethylarginine in ischemic acute kidney injury as a causative factor of renal Larginine deficiency. Transl. Res. 162: 67-76.

Beutler, E., Duron, O., and Kelly, B.M. 1963. Improved method for the determination of blood glutathione. J. Lab. Clin. Med. 61: 882-8.

Busch, M., Fleck, C., Wolf, G., and Stein, G. 2006. Asymmetrical (ADMA) and symmetrical dimethylarginine (SDMA) as potential risk factors for cardiovascular and renal outcome in chronic kidney disease-possible candidates for paradoxical epidemiology? Amino Acids, 30: 225-32.

Celermajer, D.S., Sorensen, K.E., Gooch, V.M., Spiegelhalter, D.J., Miller, O.I., Sullivan, I.D., et al. 1992. Non-invasive detection of endothelial dysfunction in children and adults at risk of atherosclerosis. Lancet, 340: 1111-5.

Chen, H.H., Lu, P.J., Chen, B.R., Hsiao, M., Ho, W.Y., and Tseng, C.J. 2015. Heme oxygenase-1 ameliorates kidney ischemia-reperfusion injury in mice through extracellular signal-regulated kinase 1/2-enhanced tubular epithelium proliferation. Biochim. Biophys. Acta, 1852: 2195-201.

Closs, E.I., Basha, F.Z., Habermeier, A., and Förstermann, U. 1997. Interference of L-arginine analogues with L-arginine transport mediated by the $y+$ carrier hCAT-2B. Nitric Oxide, 1: 65-73.

Correa-Costa, M., Amano, M.T., and Câmara, N.O. 2012. Cytoprotection behind heme oxygenase-1 in renal diseases. World J. Nephrol. 1: 4-11.

Desbuards, N., Hyvelin, J.M., Machet, M.C., Eder, V., Garrigue, M.A., Halimi, J.M., et al. .2009. Heme oxygenase-1 inducer hemin attenuates the progression of remnant kidney model. Nephron Exp. Nephrol. 113: e35-44. 
Dhanakoti, S.N., Brosnan, J.T., Herzberg, G.R., and Brosnan, M.E. 1990. Renal arginine synthesis: studies in vitro and in vivo. Am. J. Physiol. 259: E437-42.

Duarte, F., Pessoa, E.A., Reis, L.A., Schor, N., and Borges, F.T. 2016. Priming prevent nephrotoxic acute renal failure through stimulation of antioxidant defense mechanism. J. Bras. Nefrol. 38: 161-72.

Endemann, D.H., and Schiffrin, E.L. 2004. Endothelial dysfunction. J. Am. Soc. Nephrol. 15: $1983-92$. Hasdan, G., Benchetrit, S., Rashid, G., Green, J., Bernheim, J., and Rathaus, M. 2002. .Endothelial dysfunction and hypertension in 5/6 nephrectomized rats are mediated by vascular superoxide. Kidney Int. 61: 586-90.

Ishikawa, K., Sugawara, D., Wang, X.P., Suzuki, K., Itabe, H., Maruyama, Y., et al. 2001. Heme oxygenase-1 inhibits atherosclerotic lesion formation in Idl-receptor knockout mice. Circ. Res. 88: 506-12.

Kadkhodaee, M., Khastar, H., Faghihi, M., Ghaznavi, R., and Zahmatkesh, M. 2005. Effects of cosupplementation of vitamins $\mathrm{E}$ and $\mathrm{C}$ on gentamicin-induced nephrotoxicity in rat. Exp. Physiol. 90: $571-6$.

Karahan, I., Ateşşahin, A., Yilmaz, S., Ceribaşi, A.O., and Sakin, F. 2005. Protective effect of lycopene on gentamicin-induced oxidative stress and nephrotoxicity in rats. Toxicology, 215: 198-204.

Kielstein, J.T., Salpeter, S.R., Bode-Boeger, S.M., Cooke, J.P., and Fliser, D. 2006. Symmetric dimethylarginine (SDMA) as endogenous marker of renal function--a meta-analysis. Nephrol. Dial. Transplant. 21: 2446-51.

Kingma, J.G Jr., Vincent, C., Rouleau, J.R., and Kingma, I. 2006. Influence of acute renal failure on coronary vasoregulation in dogs. J. Am. Soc. Nephrol. 17: 1316-24.

Köhler, R., Eichler, I., Schönfelder, H., Grgic, I., Heinau, P., Si, H., and Hoyer, J. 2005. Impaired EDHFmediated vasodilation and function of endothelial Ca-activated K channels in uremic rats. Kidney Int. 67: 2280-7.

Lawrence, R.A., and Burk, R.F. 1976. Glutathione peroxidase activity in selenium-deficient rat liver. Biochem. Biophys. Res. Commun. 71: 952-8.

Liu, S., Lekawanvijit, S., Kompa, A.R., Wang, B.H., Kelly, D.J., and Krum, H. .2012. Cardiorenal syndrome: pathophysiology, preclinical models, management and potential role of uraemic toxins. Clin. Exp. Pharmacol. Physiol. 39: 692-700.

Lopez-Novoa, J.M., Quiros, Y., Vicente, L., Morales, A.I., and Lopez-Hernandez, F.J. 2011. .New insights into the mechanism of aminoglycoside nephrotoxicity: an integrative point of view. Kidney Int. 79: 33-45. 
Morales, A.I., Detaille, D., Prieto, M., Puente, A., Briones, E., Arévalo, M., et al. 2010. Metformin prevents experimental gentamicin-induced nephropathy by a mitochondria-dependent pathway. Kidney Int. 77: 861-9.

Mori-Kawabe, M., Yasuda, Y., Ito, M., and Matsuo, S. 2015. Reduction of NO-mediated Relaxing Effects in the Thoracic Aorta in an Experimental Chronic Kidney Disease Mouse Model. J. Atheroscler. Thromb. 22: 845-53.

Mylroie, A.A., Collins, H., Umbles, C., and Kyle, J. 1986. Erythrocyte superoxide dismutase activity and other parameters of copper status in rats ingesting lead acetate. Toxicol. Appl. Pharmacol. 82: 512-20.

Nath, K.A. 2014. Heme oxygenase-1 and acute kidney injury. Curr. Opin. Nephrol. Hypertens. 23: 1724.

Nguy, L., Nilsson, H., Lundgren, J., Johansson, M.E., Teerlink, T., Scheffer, P.G., et al. 2012. .Vascular function in rats with adenine-induced chronic renal failure. Am. J. Physiol. Regul. Integr. Comp. Physiol. 302: R1426-35.

Palm, F., Onozato, M.L., Luo, Z., and Wilcox, C.S. 2007. Dimethylarginine dimethylaminohydrolase (DDAH): expression, regulation, and function in the cardiovascular and renal systems. Am. J. Physiol. Heart. Circ. Physiol. 293: H3227-45.

Pedraza-Chaverrí, J., Maldonado, P.D., Barrera, D., Cerón, A., Medina-Campos, ON., and HernándezPando, R. 2003. Protective effect of diallyl sulfide on oxidative stress and nephrotoxicity induced by gentamicin in rats. Mol. Cell. Biochem. 254: 125-30.

Quiros, Y., Vicente-Vicente, L., Morales, A.I., López-Novoa, J.M., and López-Hernández, F.J. 2011. .An integrative overview on the mechanisms underlying the renal tubular cytotoxicity of gentamicin. Toxicol. Sci. 119: 245-56.

Rachmilewitz, D., Stamler, J.S., Karmeli, F., Mullins, M.E., Singel, D.J., Loscalzo, J., et al. 1993. Peroxynitrite-induced rat colitis--a new model of colonic inflammation. Gastroenterology, 105: 1681-8.

Smith, P.K., Krohn, R.I., Hermanson, G.T., Mallia, A.K., Gartner, F.H., Provenzano, M.D., et al. 1985. Measurement of protein using bicinchoninic acid. Anal. Biochem. 150: 76-85.

Sönmez Uydeş-Doğan, B., Topal, G., Takir, S., Ilkay, A.F., Kaleli, D., and Ozdemir, O. 2005. Relaxant effects of pravastatin, atorvastatin and cerivastatin on isolated rat aortic rings. Life Sci. 76: 177186.

Sue, Y.M., Cheng, C.F., Chang, C.C., Chou, Y., Chen, C.H., and Juan, S.H. 2009. Antioxidation and antiinflammation by haem oxygenase-1 contribute to protection by tetramethylpyrazine against 
gentamicin-induced apoptosis in murine renal tubular cells. Nephrol. Dial. Transplant. 24: 76977.

Sukhovershin, R.A., and Gilinsky, M.A. 2013. The influence of acute renal injury on arginine and methylarginines metabolism. Ren. Fail. 35: 1404-11.

Suresha, B.S., and Srinivasan, K. 2014. Fungal metabolite nigerloxin ameliorates diabetic nephropathy and gentamicin-induced renal oxidative stress in experimental rats. Naunyn Schmiedebergs Arch. Pharmacol. 387: 849-59.

Tain, Y.L., and Baylis, C. 2007. Determination of dimethylarginine dimethylaminohydrolase activity in the kidney. Kidney Int. 72: 886-9.

Takizawa, S., Hirabayashi, H., Matsushima, K., Tokuoka, K., and Shinohara, Y. 1998. Induction of heme oxygenase protein protects neurons in cortex and striatum, but not in hippocampus, against transient forebrain ischemia. J. Cereb. Blood Flow Metab. 18: 559-69.

Taye, A., and Ibrahim, B.M. 2013. Activation of renal haeme oxygenase-1 alleviates gentamicininduced acute nephrotoxicity in rats. J. Pharm. Pharmacol. 65: 995-1004.

Teerlink, T. 2005. Determination of the endogenous nitric oxide synthase inhibitor asymmetric dimethylarginine in biological samples by HPLC. Methods Mol. Med. 108: 263-74.

Wu, G., and Morris, S.M. Jr. 1996. Arginine metabolism: nitric oxide and beyond. Biochem. J. 336: 117.

Yu, Y.M., Burke, J.F., Tompkins, R.G., Martin, R., and Young, V.R. 1996. Quantitative aspects of interorgan relationships among arginine and citrulline metabolism. Am. J. Physiol. 271: E1098109. 
Table 1. Effect of hemin on body and kidney weights, kidney index and kidney and liver function tests in serum of control and gentamicin (GM)-treated rats (mean \pm SEM).

\begin{tabular}{|l|c|c|c|l|}
\hline & Control $(n=6)$ & $\operatorname{Hemin}(n=6)$ & $\mathrm{GM}(n=8)$ & $\operatorname{Hemin}+\mathrm{GM}(n=8)$ \\
\hline Initial body weight(g) & $258 \pm 4.18$ & $279 \pm 6.07$ & $276 \pm 4.26$ & $258 \pm 5.74$ \\
\hline Final body weight (g) & $263 \pm 4.00$ & $284 \pm 4.70$ & $262 \pm 7.60$ & $237 \pm 8.70$ \\
\hline Kidney weight (g) & $1.67 \pm 0.05$ & $1.87 \pm 0.06$ & $2.10 \pm 0.11^{\mathrm{a}}$ & $2.01 \pm 0.12$ \\
\hline Kidney index & $0.64 \pm 0.02$ & $0.66 \pm 0.02$ & $0.81 \pm 0.06^{\mathrm{a}}$ & $0.85 \pm 0.03^{\mathrm{a}}$ \\
\hline BUN (mg/dL) & $18.6 \pm 1.84$ & $20.0 \pm 1.24$ & $29.1 \pm 2.98^{\mathrm{a}}$ & $26.9 \pm 1.24^{\mathrm{a}}$ \\
\hline Creatinine (mg/dL) & $0.40 \pm 0.04$ & $0.33 \pm 0.02$ & $0.61 \pm 0.06^{\mathrm{a}}$ & $0.66 \pm 0.04^{\mathrm{a}}$ \\
\hline ALT (U /L) & $50.8 \pm 5.36$ & $26.7 \pm 2.98$ & $50.4 \pm 2.40$ & $37.6 \pm 4.30$ \\
\hline AST (U/L) & $89 \pm 5.80$ & $107 \pm 11.50$ & $129 \pm 18.80$ & $97 \pm 3.60$ \\
\hline
\end{tabular}

${ }^{a} p<0.05$ compared with the control group. Kidney index, kidney weight/final body weight $x 100 ;$ BUN, blood urea nitrogen; ALT, alanine aminotransferase; AST, aspartate aminotransferase

Table 2. Effect of hemin on renal oxidant and antioxidant parameters in control and gentamicin (GM)-treated rats (Mean \pm SEM)

\begin{tabular}{|c|c|c|c|c|}
\hline & Control $(n=6)$ & $\operatorname{Hemin}(n=6)$ & $\mathrm{GM}(n=8)$ & Hemin+GM $(n=8)$ \\
\hline $\begin{array}{l}\text { 4-HNE } \\
\text { (ng/mg protein) }\end{array}$ & $57.2 \pm 7.13$ & $67.0 \pm 5.36$ & $127 \pm 14.2^{\mathrm{a}}$ & $84.4 \pm 7.81^{b}$ \\
\hline $\begin{array}{l}\text { MPO } \\
(\mu \mathrm{mol} / \mathrm{g} \text { protein/min })\end{array}$ & $0.30 \pm 0.05$ & $0.58 \pm 0.25$ & $2.37 \pm 0.35^{\mathrm{a}}$ & $1.09 \pm 0.24^{\mathrm{a}, \mathrm{b}}$ \\
\hline $\begin{array}{l}\text { GSH } \\
(\mu \mathrm{mol} / \mathrm{g} \text { tissue })\end{array}$ & $1.12 \pm 0.11$ & $0.93 \pm 0.11$ & $1.47 \pm 0.10$ & $1.60 \pm 0.15^{\mathrm{a}}$ \\
\hline $\begin{array}{l}\text { SOD } \\
\text { (U/mg protein) }\end{array}$ & $17.2 \pm 1.38$ & $15.4 \pm 0.60$ & $9.31 \pm 0.96^{a}$ & $6.96 \pm 1.31^{a}$ \\
\hline $\begin{array}{l}\text { GSH-Px } \\
\text { (nmol/mg protein/min) }\end{array}$ & $323 \pm 7.70$ & $290 \pm 8.30$ & $255 \pm 6.35^{\mathrm{a}}$ & $263 \pm 12.20^{\mathrm{a}}$ \\
\hline
\end{tabular}

${ }^{a} p<0.05$ compared with the control group; ${ }^{b} p<0.05$ compared with the GM-treated group. 4-HNE,4hydroxynonenal; MPO, myeloperoxidase; GSH, glutathione; SOD. Superoxide dismutase; GSH-Px, glutathione peroxidase 
Table 3. Effect of hemin on arginine and methylated arginine derivatives in plasma and kidney and as well as dimethylarginine dimethylaminohydrolase (DDAH) activity in kidney of control and gentamicin (GM)-treated rats (mean \pm SEM).

\begin{tabular}{|c|c|c|c|c|}
\hline \multicolumn{5}{|l|}{ PLASMA } \\
\hline & Control $(n=6)$ & $\operatorname{Hemin}(n=6)$ & $\mathrm{GM}(n=8)$ & Hemin+GM $(n=8)$ \\
\hline Arginine $(\mu \mathrm{M})$ & $71.7 \pm 11.4$ & $81.9 \pm 17.8$ & $78.8 \pm 21.0$ & $84.8 \pm 24.3$ \\
\hline ADMA $(\mu \mathrm{M})$ & $0.61 \pm 0.07$ & $0.72 \pm 0.14$ & $0.66 \pm 0.10$ & $0.68 \pm 0.18$ \\
\hline SDMA $(\mu \mathrm{M})$ & $0.26 \pm 0.03$ & $0.29 \pm 0.00$ & $0.38 \pm 0.08^{\mathrm{a}}$ & $0.40 \pm 0.14^{\mathrm{a}}$ \\
\hline Arginine/ADMA & $116 \pm 4$ & $115 \pm 11$ & $119 \pm 8$ & $109 \pm 11$ \\
\hline Arginine/SDMA & $279 \pm 27$ & $279 \pm 26$ & $210 \pm 14^{a}$ & $219 \pm 18$ \\
\hline \multicolumn{5}{|l|}{ KIDNEY } \\
\hline $\begin{array}{l}\text { Arginine } \\
(\mu \mathrm{mol} / \mathrm{g} \text { protein) }\end{array}$ & $9.72 \pm 1.28$ & $8.71 \pm 1.22$ & $5.86 \pm 0.58^{\mathrm{a}}$ & $5.74 \pm 1.09^{\mathrm{a}}$ \\
\hline $\begin{array}{l}\text { ADMA } \\
\text { ( } \mu \mathrm{mol} / \mathrm{g} \text { protein) }\end{array}$ & $0.22 \pm 0.03$ & $0.21 \pm 0.02$ & $0.24 \pm 0.05$ & $0.27 \pm 0.08$ \\
\hline $\begin{array}{l}\text { SDMA } \\
\text { ( } \mu \mathrm{mol} / \mathrm{g} \text { protein) }\end{array}$ & $0.049 \pm 0.009$ & $0.045 \pm 0.006$ & $0.038 \pm 0.005^{a}$ & $0.037 \pm 0.009^{a}$ \\
\hline Arginine/ADMA & $44.6 \pm 3.81$ & $42.2 \pm 1.18$ & $24.8 \pm 1.59^{a}$ & $23.2 \pm 2.41^{\mathrm{a}}$ \\
\hline Arginine/SDMA & $199 \pm 7$ & $195 \pm 5$ & $155 \pm 4^{a}$ & $160 \pm 8^{a}$ \\
\hline $\begin{array}{l}\text { DDAH activity } \\
\text { (nmol/min/g protein) }\end{array}$ & $88.9 \pm 10.2$ & $68.2 \pm 6.1$ & $47.9 \pm 5.8^{a}$ & $95.4 \pm 3.9^{b}$ \\
\hline
\end{tabular}

${ }^{a} p<0.05$ compared with the control group; ${ }^{b} p<0.05$ compared with the GM-treated group. ADMA, asymmetric dimethylarginine; SDMA, symmetric dimethylarginine.

Table 4. The effect of gentamicin and hemin plus gentamicin treatments on the potency $\left(\mathrm{EC}_{50},-\log \mathrm{M}\right)$ and maximum relaxation $\left(E_{\max }\right)$ values of isolated rat aortic rings exposed to acetylcholine ( $\mathrm{ACh}$, an endothelium dependent vasodilator) and sodium nitroprusside (SNP, an endothelium independent vasodilator).

\begin{tabular}{|l|c|c|c|c|}
\hline \multicolumn{2}{|l|}{} & \multicolumn{2}{l|}{ SCh } & \multicolumn{2}{l|}{ SNP } \\
\hline & $\mathrm{EC}_{50}$ & $E_{\max }(\%)$ & $\mathrm{EC}_{50}$ & $E_{\max }(\%)$ \\
\hline Control & $6.94 \pm 0.35$ & $82.46 \pm 5.16$ & $8.76 \pm 0.28$ & $101.9 \pm 0.46$ \\
\hline Gentamicin & $6.48 \pm 0.04$ & $90.61 \pm 2.56$ & $8.60 \pm 0.17$ & $102.7 \pm 0.93$ \\
\hline Gentamicin+Hemin & $7.30 \pm 0.12^{\mathrm{b}}$ & $96.84 \pm 2.15^{\mathrm{a}}$ & $8.35 \pm 0.23$ & $99.55 \pm 0.48$ \\
& & & & \\
\hline
\end{tabular}

Values are the mean $\pm \mathrm{SEM}, n=6-8$ rats. $\mathrm{EC}_{50}$, the negative logarithm of the concentration $(M)$ that produced half of the maximal relaxation $\left(E_{\max }\right){ }^{\text {a" }} p<0.05$ compared with the control group; ${ }^{\mathrm{b},} p<0.05$ compared with the gentamicin treatment group. 
Table 5. The effect of gentamicin and hemin plus gentamicin treatments on the potency $\left(\mathrm{EC}_{50},-\log \mathrm{M}\right)$ and maximum contraction $\left(E_{\max }\right)$ values of rat aortic rings exposed to phenylephrine (a receptordependent contractile agent) and $\mathrm{KCl}$ (a receptor-independent contractile agent).

\begin{tabular}{|l|c|c|c|c|}
\hline & \multicolumn{2}{l|}{ Phenylephrine } & $\mathrm{KCl}$ \\
\hline & $\mathrm{EC}_{50}$ & $E_{\max }(\mathrm{g})$ & $\mathrm{EC}_{50}$ & $E_{\max }(\mathrm{g})$ \\
\hline Control & $6.99 \pm 0.11$ & $2.24 \pm 0.23$ & $27.15 \pm 4.76$ & $2.51 \pm 0.05$ \\
\hline Gentamicin & $6.28 \pm 0.09^{\mathrm{a}}$ & $1.17 \pm 0.07^{\mathrm{a}}$ & $32.81 \pm 1.83$ & $1.74 \pm 0.07^{\mathrm{a}}$ \\
\hline Gentamicin+Hemin & $6.25 \pm 0.08^{\mathrm{a}}$ & $2.00 \pm 0.16^{\mathrm{b}}$ & $27.56 \pm 2.42$ & $2.15 \pm 0.15$ \\
& & & & \\
\hline
\end{tabular}

Values are the mean $\pm \mathrm{SEM}, n=6-8$ rats. $\mathrm{EC}_{50}$, the negative logarithm of the concentration $(M)$ that produced half of the maximal contraction $\left(E_{\max }\right)$; $\mathrm{EC}_{50}$ values of $\mathrm{KCl}$ contractions are given in $\mathrm{mM},{ }^{a}, p<0.05$ compared with the control group; ${ }^{b}, p<0.05$ compared with the gentamicin treatment group.

Table 6. Semiquantitative histological score of the kidney sections in gentamicin (GM) and hemin plus GM-treated rats (mean \pm SEM)

\begin{tabular}{|l|c|c|c|c|}
\hline Histological alterations & $\begin{array}{c}\text { Control } \\
(n=6)\end{array}$ & $\begin{array}{c}\text { Hemin } \\
(n=6)\end{array}$ & $\begin{array}{c}\text { GM } \\
(n=8)\end{array}$ & $\begin{array}{c}\text { Hemin+GM } \\
(n=8)\end{array}$ \\
\hline Tubulointerstitial inflammation & 0 & 0 & $2.75 \pm 0.16$ & $1.44 \pm 0.34^{\text {b }}$ \\
\hline Tubular necrosis & 0 & 0 & $1.37 \pm 0.18$ & $0.78 \pm 0.32$ \\
\hline Tubular degeneration & 0 & 0 & $2.37 \pm 0.26$ & $1.78 \pm 0.28$ \\
\hline
\end{tabular}

Kidney sections in each rat were examined in terms of tubular inflammation, necrosis and degeneration and assigned for severity of changes using score of: 0 , absent; 1 (mild), 25\% of the fields revealed histopathological alterations; 2 (moderate), 50\% of the total fields revealed histopathological alterations; 3 (severe), $75 \%$ of the total fields revealed histopathological alterations. ${ }^{b} p<0.05$ compared with the GM-treated group. 


\section{Legends to the figures}

Figure 1.The effect of hemin on protein (A) and mRNA (B) expressions of HO-1 in kidney from GM-treated rats. Values are the mean $\pm \mathrm{SE}\left(n=6-8\right.$ male rats per group); ${ }^{\mathrm{a}}, p<0.05$ compared with the control group. Both GM and $\mathrm{GM}+$ hemin treatment caused significant increase in protein and mRNA expression of HO-1 as compared with control. There were no changes in these expressions between two groups.

Figure 2. The effect of hemin on serum levels of HO-1 in GM- treated rats ( $n=6-8$ rats per group); ${ }^{a}, p<0.05$ compared with the control group. Hemin treatment alone and combination with GM elevated serum HO-1 levels. These levels remained unchanged after GM treatment alone.

Figure 3. The concentration-response curves for acetylcholine (ACh) and phenylephrine (Phe) in aortic rings from control, GM treated and GM+hemin-treated rats. Values are the mean $\pm \mathrm{SE}(n=6-8$ rats per group).

Figure 4. Histopathologicfindings of kidney in groups. Kidney sections were obtained from four or six rats (H\&E, magnification x200). (A) Control group showing normal renal architecture. (B) Hemin group exhibiting apparent normal renal parenchyma with normal renal tubule structure and absence of necrosis and inflammatory changes. (C) GM-treated group showing severe peritubular leukocyte infiltration. (D) GM + Hemin group showing a near- normal kidney parenchyma with a small amount of inflammatory cells in the interstitial space. 


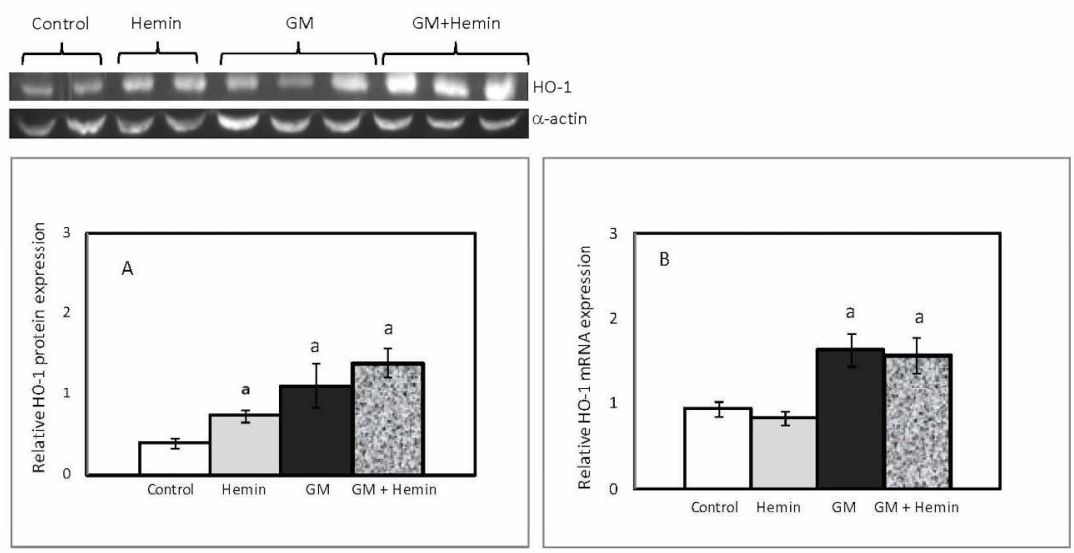

Figure 1. The effect of hemin on protein (A) and mRNA (B) expressions of HO-1 in kidney from GM-treated rats. Values are the mean \pm SE ( $n=6-8$ male rats per group); $a, p<0.05$ compared with the control group. Both GM and GM+hemin treatment caused significant increase in protein and mRNA expression of HO-1 as compared with control. There were no changes in these expressions between two groups.

$$
254 \times 190 \mathrm{~mm}(300 \times 300 \mathrm{DPI})
$$




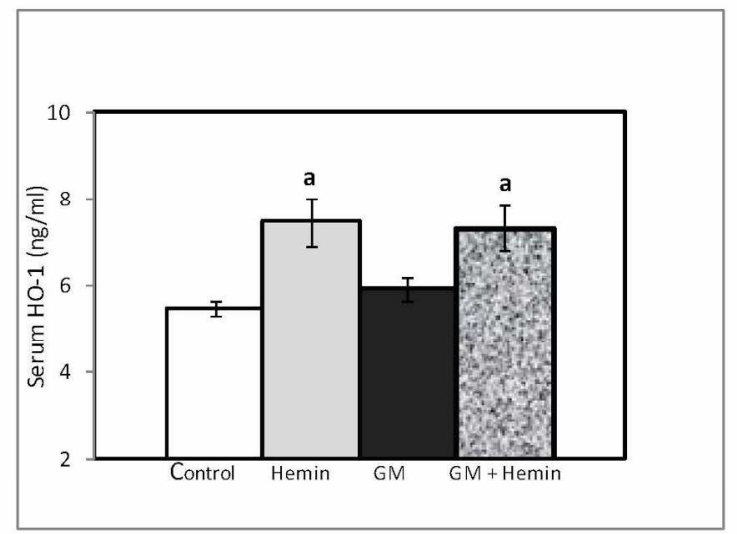

Figure 2. The effect of hemin on serum levels of HO-1 in GM- treated rats ( $n=6-8$ rats per group); a, $p<$ 0.05 compared with the control group. Hemin treatment alone and combination with GM elevated serum HO-1 levels. These levels remained unchanged after GM treatment alone.

$254 \times 190 \mathrm{~mm}(300 \times 300 \mathrm{DPI})$ 

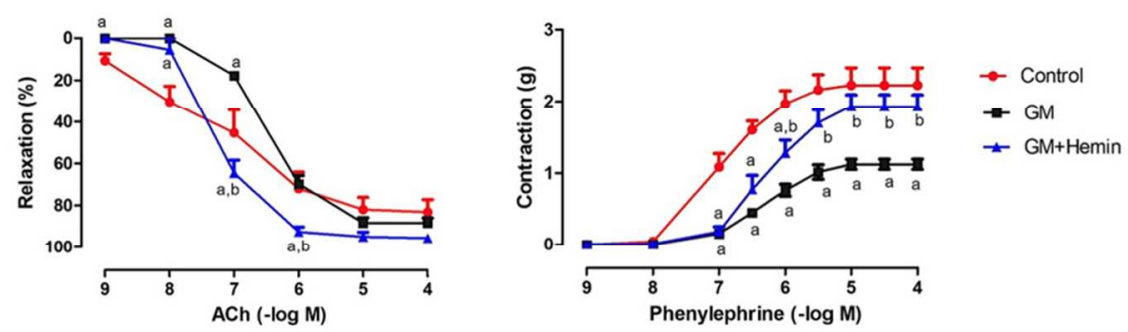

Figure 3. The concentration-response curves for acetylcholine (ACh) and phenylephrine (Phe) in aortic rings from control, GM treated and GM+hemin-treated rats. Values are the mean \pm SE ( $n=6-8$ rats per group).

\author{
$86 \times 45 \mathrm{~mm}(300 \times 300$ DPI $)$
}



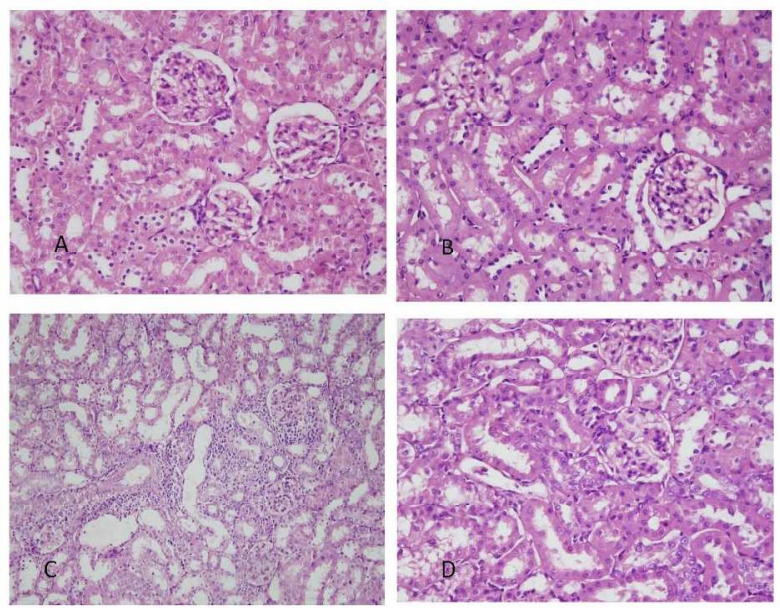

Figure 4. Histopathologicfindings of kidney in groups. Kidney sections were obtained from four or six rats (H\&E, magnification x200). (A) Control group showing normal renal architecture. (B) Hemin group exhibiting apparent normal renal parenchyma with normal renal tubule structure and absence of necrosis and inflammatory changes. (C) GM-treated group showing severe peritubular leukocyte infiltration. (D) GM + Hemin group showing a near- normal kidney parenchyma with a small amount of inflammatory cells in the interstitial space.

$254 \times 196 \mathrm{~mm}(300 \times 300$ DPI $)$ 